University of Nebraska - Lincoln

DigitalCommons@University of Nebraska - Lincoln

USDA National Wildlife Research Center - Staff Publications
U.S. Department of Agriculture: Animal and Plant Health Inspection Service

August 2001

\title{
Analysis of Pesticide Gas Cartridges
}

John J. Johnston

APHIS/WS/National Wildlife Research Center, U.S. Department of Agriculture

Carol A. Furcolow

APHIS/WS/National Wildlife Research Center, U.S. Department of Agriculture

Doreen G. Griffin

APHIS/WS/National Wildlife Research Center, U.S. Department of Agriculture

Randal S. Stahl

USDA-APHIS-Wildlife Services, randal.s.stahl@aphis.usda.gov

John D. Eisemann

USDA/APHIS/WS National Wildlife Research Center, John.D.Eisemann@aphis.usda.gov

Follow this and additional works at: https://digitalcommons.unl.edu/icwdm_usdanwrc

Part of the Environmental Sciences Commons

Johnston, John J.; Furcolow, Carol A.; Griffın, Doreen G.; Stahl, Randal S.; and Eisemann, John D., "Analysis of Pesticide Gas Cartridges" (2001). USDA National Wildlife Research Center - Staff Publications. 539. https://digitalcommons.unl.edu/icwdm_usdanwrc/539

This Article is brought to you for free and open access by the U.S. Department of Agriculture: Animal and Plant Health Inspection Service at DigitalCommons@University of Nebraska - Lincoln. It has been accepted for inclusion in USDA National Wildlife Research Center - Staff Publications by an authorized administrator of DigitalCommons@University of Nebraska - Lincoln. 


\title{
Analysis of Pesticide Gas Cartridges
}

\author{
J ohn J . J ohnston,* Carol A. Furcolow, Doreen G. Griffin, Randal S. Stahl, and \\ J ohn D. Eisemann
}

APHISNS/National Wildlife Research Center, U.S. Department of Agriculture, 4101 LaPorte Avenue, Fort Collins, Colorado 80521

\begin{abstract}
Charcoal and sodium nitrate, the active ingredients in pesticide gas cartridges, are quantified via carbon analysis and ion chromatography, respectively. Linearity was excellent $\left(R^{2}>0.995\right)$ over a range consisting of $50-150 \%$ of the target concentration for both ingredients. The coefficient of variation for the replicate analyses of gas cartridges over multiple days was $<4 \%$ for both analytes. Using the results from the analysis of two batches of gas cartridges, theoretical populations were modeled and used to determine practical sampling strategies to support a quality control program for a gas cartridge manufacturing operation. This modeling indicates that the analysis of three cartridges from each of five different lots would produce mean values for both active ingredients that are within $5 \%$ of the true mean $>99 \%$ of the time.
\end{abstract}

Keywords: Gas cartridge; rodenticide; predacide; nitrate; charcoal; carbon; sampling

\section{INTRODUCTION}

Gas cartridges are used to manage pest rodent and predator populations on rangeland, forest, and ornamental turf such as golf courses and corporate lawns. Target species include moles, ground squirrels, woodchucks, prairie dogs, coyotes, and marmots. Many gas cartridges consist of a cardboard tube that contains the active ingredients sodium (or potassium) nitrate and charcoal. During use, ignited cartridges burn to produce carbon monoxide. Additional ingredients such as fuller's earth and/or borax may be added to control the rate of burn $(1,2)$. The U.S. Environmental Protection Agency (EPA) requires that chemical analyses be conducted to confirm that the concentrations of the active ingredients in the manufactured cartridges conform to the Confidential Statement of Formulation (3). The U.S. Department of Agriculture (USDA), National Wildlife Research Center (NWRC), Analytical Chemistry Project provides analyses to fulfill this requirement for gas cartridges containing fuller's earth and borax manufactured at the USDA's Pocatello Supply Depot.

Previous methodology separated the water-soluble sodium nitrate from the water-insoluble charcoal by octanol/water partitioning of the gas cartridge contents (4). Sodium nitrate was then quantified by ion chromatographic analysis of the aqueous phase. The charcoal was recovered from the octanol by filtration. Recovered charcoal was subsequently dried and quantified by gravimetric analysis. The entire charcoal assay (from preparation of the filter paper through the final weighing) often required 5 days to complete. Historically, quality control (QC) recoveries for sodium nitrate averaged around $100 \%$ with coefficients of variation (CV) of $\sim 2 \%$. QC recoveries for charcoal were typically $>110 \%$ with CVs as high as $25 \%$. It is believed these high CV values were attributed to the inactive gas cartridge ingredients contributing to the gravimetric determination for charcoal.

In an attempt to improve the accuracy, precision, and efficiency, we evaluated ashing and carbon analysis for the quantification of charcoal in gas cartridges. Carbon analysis produced significant improvements in accuracy and precision for charcoal determination. Computer modeling was used to estimate the precision of mean charcoal and sodium nitrate values associated with a variety of sampling strategies.

\section{MATERIALS AND METHODS}

Sample Preparation. The outer cardboard cylinder of a gas cartridge was pounded with a rubber mallet to loosen the contents of the gas cartridge. The contents $(\sim 165 \mathrm{~g})$ were blended in a standard household type blender on low for $\sim 2$ min. An aliquot $(\sim 50 \mathrm{~g})$ was removed and transferred to a hand-held coffee mill. The gas cartridge contents were then ground for $\sim 30 \mathrm{~s}$ to produce a fine powder.

Charcoal Analysis. The carbon contents of charcoal and gas cartridge contents were determined using ASTM D5373 (5). Aliquots of the double-ground (blender/coffee mill) gas cartridge contents ( $\sim 70 \mathrm{mg}$ ) or charcoal $(\sim 50 \mathrm{mg}$ ) were transferred to a combustion crucible. The crucible contents were combusted to carbon dioxide $\left(\mathrm{CO}_{2}\right)$ at $1370{ }^{\circ} \mathrm{C}$ using a LECO (St. J oseph, MI) CR-12 carbon analyzer. $\mathrm{CO}_{2}$ was subsequently detected via infrared detection. Oxygen (10 psi) was used as a carrier gas. Percent carbon was determined via a calibration curve (detector response versus percent carbon) constructed from the analysis of external standards (calcium carbonate, NIST Buffalo River Sediment 2704, synthetic carbon, and sucrose). The percent charcoal in the gas cartridge contents was determined by dividing the carbon content of the gas cartridge contents by the carbon content of the pure charcoal.

Nitrate Analysis. An aliquot ( $1.00 \mathrm{~g})$ of the doubleground gas cartridge contents was transferred to a $50 \mathrm{~mL}$ nalgene centrifuge tube followed by the addition of $30 \mathrm{~mL}$ of deionized (DI) water. The centrifuge tube was capped, shaken by hand for $\sim 30 \mathrm{~s}$, and permitted to stand at room temperature for 15 $\min$. The tube was then centrifuged at $5100 \mathrm{~g}$ for $2 \mathrm{~min}$ and the supernatant transferred to a $250 \mathrm{~mL}$ volumetric flask. The sample was again extracted and centrifuged, and the supernatants were combined. The volumetric flask contents were diluted to volume with DI water. Using a $10 \mathrm{~mL}$ disposable syringe and a $0.45 \mu \mathrm{m}$ nylon filter, $\sim 8 \mathrm{~mL}$ of the extract was filtered into a $10 \mathrm{~mL}$ test tube. Using a volumetric pi pet, 2.00 
$\mathrm{mL}$ of the filtered extract was transferred to a $100 \mathrm{~mL}$ volumetric flask. The flask contents were diluted to volume with DI water, capped, and mixed by hand. Aliquots were transferred to $8 \times 35 \mathrm{~mm}$ autosampler tubes for analysis via ion chromatography.

Ion Chromatography. Nitrate was quantified by ion chromatographic analysis of $20 \mu \mathrm{L}$ aliquots of the aqueous gas cartridge extract using a Dionex (Sunnyvale, CA) series 4500i ion chromatograph equipped with a Dionex anion micromembrane suppressor. Nitrate was separated on a $4 \mathrm{~mm}$ i.d. $\times 25$ $\mathrm{cm}$ Dionex AS4A anion separator ion chromatography column (10 $\mu \mathrm{m}$ particle size). A mobile phase of $1.8 \mathrm{mM} \mathrm{Na}_{2} \mathrm{CO}_{3} / 1.7$ $\mathrm{mM} \mathrm{NaHCO}_{3}$ was used at a flow rate of $2 \mathrm{~mL} / \mathrm{min}$. The regenerant consisted of $25 \mathrm{mN} \mathrm{H} \mathrm{SO}_{4}$ at a flow rate of 2.5$3.0 \mathrm{~mL} / \mathrm{min}$. Nitrate was quantified using conductivity detection and a calibration curve (detector response versus nitrate concentration) constructed from the analysis of external standards ranging from 20 to $80 \mu \mathrm{g}$ of sodium nitrate/mL of water.

Accuracy, Linearity, Ruggedness, and Interferences. To determine the accuracy and linearity of the charcoal analysis, a homogeneous mixture consisting of $73.6 \%$ sodium nitrate, $12.5 \%$ borax, and $13.9 \%$ fuller's earth was prepared by mixing in a blender. This homogeneous mixture was blender mixed with charcoal to prepare $10 \mathrm{~g}$ batches containing 10 , $15,28,45$, and $50 \%$ charcoal. A single sample of each $10 \mathrm{~g}$ batch was analyzed. By using this approach, the ratio of sodium nitrate, borax, and fuller's earth in each sample was identical to the target ratios in the manufactured gas cartridges. Percent charcoal versus percent carbon and percent charcoal observed versus percent charcoal were analyzed by linear regression using MS Excel (6). Similarly, for sodium nitrate analysis, a mixture containing charcoal, borax, and fuller's earth at $59.55,19.15$, and $21.30 \%$, respectively, was mixed with sodium nitrate to produce three $10 \mathrm{~g}$ batches containing 25,50 , and $75 \%$ sodium nitrate. This produced mixtures with ratios of charcoal, borax, and fuller's earth that were identical to the target ratios in the manufactured gas cartridges. Seven aliquots of each mixture were analyzed by ion chromatography and observed versus actual percent nitrate concentrations were analyzed by linear regression. To determine the possibility of interferences due to other ingredients, carbon analyses were also conducted on sodium nitrate, borax, and fuller's earth.

To evaluate method repeatability or method ruggedness, a mixture consisting of target concentrations of sodium nitrate (53\%), charcoal (28\%), fuller's earth (10\%), and borax (9\%) was prepared. For sodium nitrate analysis, three aliquots were analyzed on six separate days. For charcoal analysis, three aliquots were analyzed on four separate days. Additionally, seven subsamples from a commercially available gas cartridge were analyzed for sodium nitrate and charcoal on a single day.

Sampling Strategies. According to U.S. EPA product testing guidelines, gas cartridges must be sampled and analyzed from five different production lots (3). However, there are no guidelines that specify the number of samples that should be analyzed from each lot. To determine the optimal number of cartridges to sample from each lot, one dozen cartridges were randomly selected from each of two lots of gas cartridges. E ach lot consisted of 285 cartridges. The charcoal and sodium nitrate contents of each cartridge were quantified as previously described. The resulting data for both lots were combined and treated as representative of the population to be modeled. The data were then analyzed with a bootstrapping technique (7) using Resampling Stats software (Resampling Stats, Inc., Arlington, VA). The nitrate and charcoal percent compositions of the gas cartridges were modeled independently. Lots of 285 cartridges were randomly generated from the percent composition data, and the mean percent charcoal and percent sodium nitrate for 5000 of these model ed lots were calculated. A model was devel oped to determine appropriate sample size to achieve a reasonable probability of selecting a sufficient number of cartridges from each lot such that the mean estimated charcoal and sodium nitrate concentrations from this sample would fall within $3 \%$ of the model ed popula-
Table 1. Standard Certified Limits

\begin{tabular}{llc}
\hline \multirow{2}{*}{$\begin{array}{c}\text { nominal concn of } \\
\text { ingredient }(\mathrm{N})\end{array}$} & \multicolumn{2}{c}{ certified limits for ingredient } \\
\cline { 2 - 3 } & upper limit & lower limit \\
\hline $\mathrm{N} \leq 1.0 \%$ & $\mathrm{~N}+10 \% \mathrm{~N}$ & $\mathrm{~N}-10 \% \mathrm{~N}$ \\
$1 \%<\mathrm{N} \leq 20 \%$ & $\mathrm{~N}+5 \% \mathrm{~N}$ & $\mathrm{~N}-5 \% \mathrm{~N}$ \\
$20 \%<\mathrm{N} \leq 100 \%$ & $\mathrm{~N}+3 \% \mathrm{~N}$ & $\mathrm{~N}-3 \% \mathrm{~N}$
\end{tabular}

tion mean. The model randomly generated 5000 samples of the data with sample sizes of $15,20,25$, and 50 cartridges. The means for percent charcoal and percent sodium nitrate were calculated for each of these samples. The number of times the sample mean fell within $\pm 3 \%$ of the population means for sodium nitrate and charcoal was subsequently determined. Similar analyses were calculated using a sample criteria of $\pm 5 \%$.

\section{RESULTS AND DISCUSSION}

EPA product property test guidelines require the testing of five separate batches of a manufactured pesticide product (3). EPA guidelines for certification limits on pesticide products are listed in Table 1 . These guidelines require testing and documentation to prove that the sodium nitrate and charcoal concentrations in the manufactured product do not differ from the nominal concentrations by $> \pm 3 \%$. As the manufacturing targets for sodium nitrate and charcoal are 53 and $28 \%$, respectively, this prompted us to develop an analytical method that was capable of providing data to document that the mean charcoal concentration of the gas cartridges is between 25 and $31 \%$ and that the mean sodium nitrate concentration falls between 50 and $56 \%$.

An atypical challenge associated with this method is that charcoal, an analyte of interest, is a variable and heterogeneous substance. Carbon analysis of samples from eight different batches of charcoal yielded a range of carbon contents from 70.45 to $75.05 \%$. As the carbon content of the charcoal is used to convert the percent carbon data to percent charcoal, it is imperative that the pure charcoal analyzed be representative of the actual material used to produce the gas cartridges.

To test for potential interferences, all gas cartridge ingredients were initially analyzed for carbon and nitrate. Sodium nitrate was the only component that produced a chromatographic response at the retention time for nitrate. With respect to carbon analyses, borax and nitrate yiel ded carbon levels bel ow the method limit of detection $(0.05 \%$ carbon $=3 \times$ instrument response for a blank). Analysis of fuller's earth indicated a carbon content of $0.88 \%$. As fuller's earth constitutes only $10 \%$ of the formulation, carbon contribution from fuller's earth would contribute only $0.09 \%$ to the total carbon content of the formulation. Given that the CV for the carbon analysis was $\sim 1.5 \%$, we deemed the potential contribution of $0.09 \%$ carbon content of the fuller's earth to be insignificant.

Linearity. The target concentrations of the manufactured gas cartridge components are $28 \%$ charcoal, $53 \%$ sodium nitrate, $9 \%$ borax, and $10 \%$ fuller's earth. Linearity for quantification of charcoal and sodium nitrate was determined over a range of approximately $50-150 \%$ of the target concentrations. The carbon analyzer produced a linear response (detector response versus percent carbon) for the analysis of the external standards ( $\left.R^{2}>0.995\right)$. As indicated by Figure 1 , there is a highly significant linear relationship between the charcoal content of the gas cartridges and the results of the carbon analysis $\left(R^{2}>0.995\right)$. Additionally, visual 


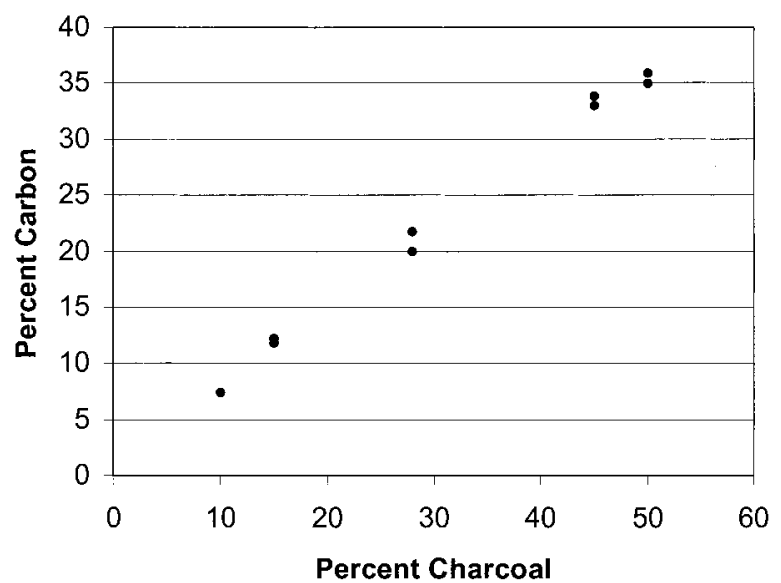

Figure 1. Percent carbon versus percent charcoal from the analysis of gas cartridge mixtures.

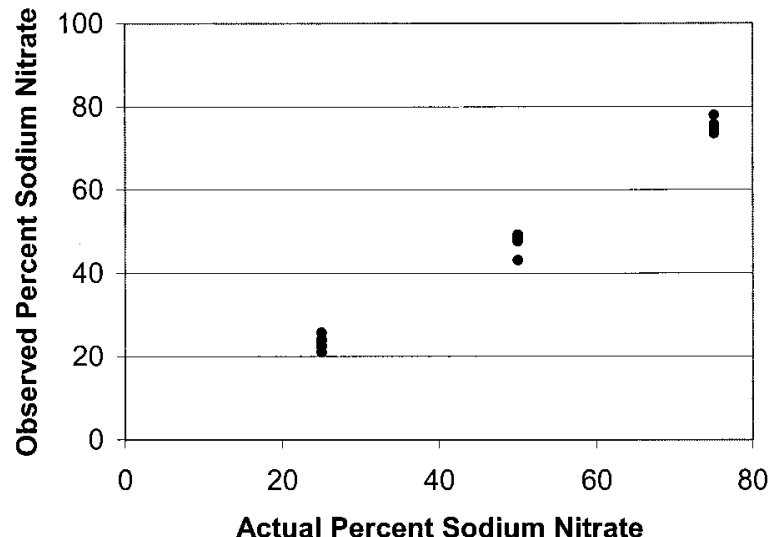

Figure 2. Observed versus actual percent sodium nitrate from the analysis of gas cartridge mixtures.

inspection of the plotted data indicated that the residuals were normally distributed. Additionally, the ratio of carbon/charcoal concentration was nearly constant (CV $<0.05 \%)$ throughout the tested range. Linear regression of the log percent charcoal versus log percent carbon plot yielded a slope equal to 1 ( $p<0.001$ ), suggesting a proportional relationship between these variables. Similarly, the ion chromatography system produced a linear response (detector response versus percent sodium nitrate) for the analysis of the external sodium nitrate standards $\left(R^{2}>0.995\right)$. The linear regression data presented in Figure 2 shows a highly significant linear relationship between the actual and the calculated sodium nitrate concentrations of the gas cartridge contents $\left(R^{2}>0.993\right)$. Linear regression of the log observed percent sodium nitrate versus the log actual percent sodium nitrate plot yielded a sl ope equal to 1 ( $p<0.001)$, suggesting a proportional relationship between these variables.

Ruggedness. Twelve replicates of quality control prepared gas cartridge content mixture (containing target concentrations of all ingredients) were analyzed on four separate days. These analyses yielded a mean recovery of $100.7 \%$ with a CV of $2.6 \%$. The analysis of seven replicates of a commercially available gas cartridge yielded a CV of only $1.5 \%$. Eighteen replicates of the quality control prepared gas cartridge content mixture were analyzed for sodium nitrate on six separate analysis days. The mean sodium nitrate recovery was $95.3 \%$ with a CV of $4.3 \%$. The analysis of seven replicates of a commercially available gas cartridge
Table 2. Effect of Sample Size on Accuracy

\begin{tabular}{cccccc}
\hline \multirow{2}{*}{$\begin{array}{c}\text { samples } \\
\text { per lot }\end{array}$} & \multicolumn{2}{c}{$\begin{array}{c}\text { frequency (\%) } \\
\text { of mean } \pm 3 \%\end{array}$} & & \multicolumn{2}{c}{$\begin{array}{c}\text { frequency }(\%) \\
\text { of mean } \pm 5 \%\end{array}$} \\
\cline { 2 - 3 } \cline { 5 - 6 } \cline { 5 - 6 } & charcoal & sodium nitrate & & charcoal & sodium nitrate \\
\hline 10 & $99+$ & $99+$ & & $99+$ & $99+$ \\
5 & 96 & 98 & & $99+$ & $99+$ \\
4 & 93 & 97 & & $99+$ & $99+$ \\
3 & 90 & 93 & & $99+$ & $99+$ \\
2 & 82 & 87 & & 97 & 98 \\
1 & 62 & 72 & & 87 & 87
\end{tabular}

resulted in a CV of 3.6\%. Overall, this approach represents a significant improvement with respect to the gravimetric determination of charcoal content in gas cartridges.

Sampling Strategy. To determine the most efficient sampling strategy, 12 gas cartridges were randomly selected from two batches of gas cartridges. Carbon analysis indicated mean charcoal contents of $25.3 \%$ (CV $=8.4 \%)$ and $26.7 \%(\mathrm{CV}=5.8 \%)$ for the two lots. Ion chromatography analysis indicated mean sodium nitrate concentrations of $59.7 \%(\mathrm{CV}=5.9 \%)$ and $58.8 \%(\mathrm{CV}=$ $7.1 \%)$. These data were used to generate a theoretical population of 5000 lots. Lots of 285 cartridges were then randomly generated from the percent composition data, and the mean charcoal and sodium nitrate contents for 5000 lots were calculated. A model was developed to determine appropriate sample size to achieve a reasonable probability of selecting a sufficient number of cartridges from each lot so that the mean from this sample would fall within $3 \%$ of the population mean. The model randomly generated 5000 samples of the data with sample sizes of $15,20,25$, and 50 cartridges. The mean charcoal and sodium nitrate composition was calculated for each of these samples. As indicated by the data in Table 2, the number of times the sample mean fell within $\pm 3 \%$ of the population means for sodium nitrate and charcoal was determined. To obtain a mean value for charcoal and sodium nitrate that falls within $3 \%$ of the actual value at least $99 \%$ of the time would require the analysis of 10 samples per lot (50 samples total). For our laboratory, this sampling level would be possible to support an initial registration effort. However, as an ongoing quality control program, this level of sampling would be tedious. Table 2 also indicates that when one and two gas cartridges from a lot are sampled, the calculated sample mean for both active ingredients falls within $\pm 5 \%$ of the true mean $<99 \%$ of the time. As we prefer a higher level of precision, we adopted a sampling scheme of three cartridges per lot (15 total), analyzing one subsample from each cartridge. This approach should generate mean values for charcoal and sodium nitrate that are within $5 \%$ of the true value $>99 \%$ of the time. With respect to manufacturing gas cartridges, this level of precision and accuracy should be suitable for the production of a consistently performing product.

\section{LITERATURE CITED}

(1) Matschke, G. H.; Ramey, C. A.; McCann, G. R. Evaluation of the 2-Active Ingredient Gas Cartridge for Controlling Northern Pocket Gophers. Presented at the WRRC-95 Annual Meeting, N ov 16-17, Reno, NV, 1994.

(2) Dolbeer, R. A.; Bernhardt, G. E.; Seamans, T. W.; Woronecki, P. P. Efficacy of Two Gas Cartridge F ormulation in Killing Woodchucks in Burrows. Wild. Soc. Bull. 1991, 19, 200-204. 
(3) U.S. Environmental Protection Agency. Data Require ments for Registration, Subpart C, Product Chemistry Data Requirements, Section 158.175, Certified Limits; U.S. GPO: Washington, DC, 1997; 3 pp.

(4) U.S. Department of Agriculture/Animal Plant Health Inspection Service/Wildlife Services/National Wildlife Research Center. NWRC Analytical Method 40A, "Gas CartridgeF ormulation Assay"; U.S. GPO: Washginton, DC, 1997; 11 pp.

(5) American Society for Test Methods. Instrumental De termination of Carbon, Hydrogen and Nitrogen in Laboratory Samples of Coal and Coke; ASTM: Philadelphia, PA, 1997; ASTM D5373-93.
(6) Microsoft Excel/Microsoft Office. Microsoft Corp. Redmond, WA, 2000.

(7) Simon, J . L. Resampling: New Statistics; Resampling Stats, Inc.: Arlington, VA, 1997.

Received for review March 28, 2001. Revised manuscript received J une 9, 2001. Accepted J une 17, 2001. Mention of specific products is for informational purposes and does not imply endorsement by the federal government.

J F $010413 Z$ 